\title{
Recommendations of protective measures for orthopedic surgeons during COVID-19 pandemic
}

\author{
Yulong Wang ${ }^{1}$ - Lian Zeng ${ }^{1}$ - Sheng Yao ${ }^{1}$. Fengzhao Zhu ${ }^{1}$. Chaozong Liu ${ }^{2}$ - Anna Di Laura ${ }^{2}$. Johann Henckel ${ }^{2}$. \\ Zengwu Shao ${ }^{1}$. Michael T. Hirschmann ${ }^{3} \cdot$ Alister Hart $^{2} \cdot$ Xiaodong Guo $^{1}$ (b)
}

Received: 12 May 2020 / Accepted: 4 June 2020 / Published online: 10 June 2020

(c) European Society of Sports Traumatology, Knee Surgery, Arthroscopy (ESSKA) 2020

\begin{abstract}
Purpose It was the primary purpose of the present systematic review to identify the optimal protection measures during COVID-19 pandemic and provide guidance of protective measures for orthopedic surgeons. The secondary purpose was to report the protection experience of an orthopedic trauma center in Wuhan, China during the pandemic.

Methods A systematic search of the PubMed, Cochrane, Web of Science, Google Scholar was performed for studies about COVID-19, fracture, trauma, orthopedic, healthcare workers, protection, telemedicine. The appropriate protective measures for orthopedic surgeons and patients were reviewed (on-site first aid, emergency room, operating room, isolation wards, general ward, etc.) during the entire diagnosis and treatment process of traumatic patients.

Results Eighteen studies were included, and most studies (13/18) emphasized that orthopedic surgeons should pay attention to prevent cross-infection. Only four studies have reported in detail how orthopedic surgeons should be protected during surgery in the operating room. No detailed studies on multidisciplinary cooperation, strict protection, protection training, indications of emergency surgery, first aid on-site and protection in orthopedic wards were found.

Conclusion Strict protection at every step in the patient pathway is important to reduce the risk of cross-infection. Lessons learnt from our experience provide some recommendations of protective measures during the entire diagnosis and treatment process of traumatic patients and help others to manage orthopedic patients with COVID-19, to reduce the risk of crossinfection between patients and to protect healthcare workers during work.
\end{abstract}

Level of evidence IV.

Keywords 2019 novel coronavirus $\cdot$ Novel coronavirus disease $\cdot 2019$-nCoV $\cdot$ COVID-19 $\cdot$ Fracture $\cdot$ Treatment and diagnosis $\cdot$ Cross-infection · Protection · Orthopedic surgery $\cdot$ Traumatology

\section{Introduction}

Yulong Wang and Lian Zeng have contributed equally to this paper, and considered as first co-authors.

Xiaodong Guo

xiaodongguo@hust.edu.cn

1 Department of Orthopedics, Union Hospital, Tongji Medical College, Huazhong University of Science and Technology, 1227 Jiefang Avenue, Wuhan 430022, People's Republic of China

2 Royal National Orthopedic Hospital (RNOH) NHS Trust, University College London (UCL) Stanmore Campus, Brockley Hill, Stanmore, Middx, London HA7 4LP, UK

3 Department of Orthopedic Surgery and Traumatology, Kantonsspital Baselland (Bruderholz, Liestal, Laufen), Bruderholz, Switzerland
In December 2019, the Coronavirus Disease 2019 (COVID19) caused by coronavirus (2019-nCoV) was found in Wuhan (Hubei, China) [44] and then became a worldwide pandemic on 11th March 2020. Compared with severe acute respiratory syndrome (SARS) coronavirus, COVID-19 has a lower mortality, but it is more infectious and pathogenic $[4,31,36]$. According to statistics from Johns Hopkins University [24], a total of 4,136,056 cases of COVID-19 have been confirmed globally until 11 May, 2020. Due to the high infectivity of 2019-nCoV, the source of infection can be COVID-19 patients and asymptomatic infected people. The main routes of transmission of 2019-nCoV are respiratory droplets, close contact and aerosol transmission [4, 17, 31-33, 36, 45]. Furthermore, COVID-19 has a latent period 
of 1-14 days, up to 24 days [17]. Therefore, in the process of patient treatment and diagnosis, there is a high risk of cross-infection to healthcare workers [19].

The pandemic of COVID-19 has brought great challenges at every step in the patient pathway, from pre-hospital, emergency diagnosis and treatment, emergency surgery, anesthesia, and perioperative management. In every step of treatment, the strategies for the treatment of trauma patients should be formulated and protective measures should be taken. What PPE should be worn, and what preventive steps should be undertaken by healthcare workers in different areas of the patient pathway?

Hence, we performed the present systematic review that aimed to identify the optimal protection measures during COVID-19 pandemic and provide guidance of protective measures for orthopedic surgeons. The secondary purpose was to report the protection experience of an orthopedic trauma center in Wuhan, China. As of March 26, 2020, a total of 23,187 cases with COVID-19 including rescuing 1,134 cases of acute and critical illness and more than 400 patients with ventilators have been treated in our institution (Hubei, China) located in the center of the epidemic; meanwhile, various surgeries are performed in more than 300 cases with COVID-19. The Orthopedic Department has handled more than 260 emergency cases. Recommendations of protective measures was developed in a learning by doing and consensus process $[14,17,20,26,31-33,37,42,45$, 48]. This paper also describes what was done and how it was implemented.

\section{Materials and methods}

A systematic review of the available literature was performed for articles published up to April 27, 2020 using the keyword terms "COVID-19", "fracture", "trauma", "orthopedic", "surgeon", "healthcare workers", "protection", "telemedicine" in several combinations. The following databases were assessed: PubMed, Cochrane, Web of Science, Google Scholar, and all the publications were searched. The search was limited to English studies only. Studies in other languages were not included in this review.

\section{Study selection}

All peer-reviewed articles were considered. Randomized controlled trials (RCTs), prospective trials and retrospective studies as well as reviews and case reports were included in this systematic review. Two authors independently screened the titles and abstracts of all the articles were identified. If the abstract and the full-text was unavailable, the paper was excluded. In the event of disagreement, a consensus was reached by discussion, if needed with the intervention of the senior author.

This systematic review was conducted in accordance with the established guidelines from Preferred Reporting Items for Systematic Reviews and Meta-analysis (PRISMA). However, due to the heterogeneity of available data, it was decided to present the review in a narrative manner.

\section{Data extraction}

One author extracted data from all the selected original articles, which was repeated by two other authors. If there was no agreement between the three, the senior author was consulted. Where required, the corresponding authors were contacted for additional information. This review focused on protective measures in the entire diagnosis and treatment process. At each stage of the literature search, a kappa value was calculated to determine inter-reviewer agreement on study selection. Pertinent information extracted included author, date and journal of publication, study design (and level of evidence). Descriptive statistics, such as the means, ranges, and measures of variance [e.g., standard deviations (SD)], are presented where applicable.

\section{Results}

The initial literature search found 176 articles. After removing 23 duplicates, 153 studies were screened. Of the 153 studies, 126 were excluded after screening of the title and abstract. Additional 9 studies were excluded after full-text review. Thus, 18 articles were finally eligible for data extraction. Agreement between the reviewers on study selection was substantial at the title review stage $(k=0.705 ; 95 \%$ CI $0.563-0.828$ ), almost perfect at the abstract review stage ( $k=0.871,95 \%$ CI $0.475-0.999)$, and perfect at the full-text review stage $(k=1.0)$. Based on the analysis of levels of evidence, one study was classified as level III, fourteen studies were classified as level IV and the remaining three studies were classified as level V. Due to study design heterogeneity it was not possible to pool results across studies and perform a meta-analysis.

Only one case series study reported 10 fracture patients ( 8 women and 2 men) with COVID-19, for which the mean age was $68.4 \pm 17.5$ years old (range 34-87). Eight (80\%) with complications such as hypertension, diabetes, brain injury, etc., and 4 (40\%) patients eventually died [29]. It indicated that enormous challenges to treat patients with traumatic fracture are given to orthopedic surgeons during COVID19 pandemic. Many studies [1, 27, 28, 30, 39, 50] reported that using video or teleconference for morning rounds, electronic consultations, videoconferencing, digital outpatient and other telemedicine methods to provide medical guidance 
and follow-up instruction for patients can reduce unnecessary contact, limiting the spread of the virus and save protective materials.

Two surveys of surgeons found that the kind of protective measures should be taken and how to or not to screen patients with COVID-19 are different in different countries or different departments $[16,30]$. Another survey of COVID-19 disease among orthopedic surgeons from 8 hospitals in Wuhan found a total of 26 surgeons were diagnosed with COVID-19 [19], and the incidence varied from 1.5 to $20.7 \%$. Training on prevention measures and wearing of respirator masks was found to be protective. Not wearing an N95 respirator was a risk factor for infection with COVID19 as well as severe fatigue due to work overload [19].

Delaying and canceling elective surgery, and the exact definition of emergency surgery are still under debate [1, $11,13,14,16,27,29,37,39,42,50]$. Emergency surgery in the context of the current crisis can be defined as urgent pathologies that could result in long-term disability and/or chronic pain if surgery is postponed [14, 35, 37]. Trauma related fractures are the most common cause of emergency surgery $[5,6,9,12,21,23,38,47]$. The WHO and evidencebased literature have not given any detailed recommendations for emergency orthopedic treatment during COVID-19 pandemic.

There was no study concerning the management of an outpatient clinic and surgical activities and the challenges in handling with a high-volume practice during epidemic. Only one article offered important points and strategies to provide the highest level of safety to healthcare workers during the start-up phase [13].

Most studies (13/18) emphasized that orthopedic surgeons should pay attention to personal protection when facing the COVID-19 pandemic to prevent cross-infection [1, $11,13,14,16,19,20,27,34,35,39,42,50]$. Four studies have reported in more detail on personal protection $[1,11$, $20,35]$ (Table 1). There are no studies about the level of protection should be recommended for orthopedic surgeon from on-site emergency to patient discharge. Only Hirschmann et al. [20] gave an evidence-based recommendation on which PPE should be used to avoid occupational transmission of COVID-19 during surgery.

\section{Discussion}

During the COVID-19 pandemic, orthopedic patients as well as medical staff may be infected with COVID-19 when they are exposed to people infected with COVID-19 during their work. Transmission from medical staff to medical staff, patient to medical staff, as well as medical staff to patient, has been demonstrated. The most commonly suspected areas of exposure during the entire diagnosis and treatment process were general wards, followed by public places at the hospital, operating rooms, the intensive care unit, and the outpatient clinic [19]. To avoid occupational transmission of COVID-19 to medical staff, appropriate protective measures taken by orthopedic surgeons during pandemic in different sites from pre-hospital, emergency diagnosis and treatment, emergency surgery, anesthesia, and perioperative management are of great importance.

\section{On-site first aid}

In principle, all patients with fractures which occurred in pandemic areas should be treated as suspected COVID-19 cases $[11,35,46]$. The ambulance requires sufficient protective equipment and rescue equipment [32]. All medical personnel should be familiar with the symptoms of COVID19 and should have received professional training in levelthree personal protective equipment (PPE) [11, 19, 20, 29, $31,34,35,45]$ (Table 2). In addition, all should be educated well in wearing and taking off a disposable hat, disposable protective clothing, long shoe cover, N95/FFP2 mask, goggles, double-layer gloves and protective face screen. PPE is important to minimize the chance of contact with body

Table 1 Summaries of main points of the studies

\begin{tabular}{|c|c|c|}
\hline Authors & $\begin{array}{l}\text { Level of } \\
\text { evidence }\end{array}$ & Main points of the studies \\
\hline Hirschman et al. & IV & $\begin{array}{l}\text { Make recommendations and detailed introduction for personal protective equipment and safety recommen- } \\
\text { dations for orthopedic surgeons and trauma surgeons. Strict protective measures should be taken during } \\
\text { surgery to avoid occupational transmission of COVID-19 to the surgical team by surgical aerosol }\end{array}$ \\
\hline Rodrigues-Pinto et al. & $\mathrm{V}$ & $\begin{array}{l}\text { Share their experience of management in the COIVD-19 dedicated operating room, and perform different } \\
\text { sterile procedures in different zones of operating room to reduce the risk of cross-infection }\end{array}$ \\
\hline Awad et al. & IV & $\begin{array}{l}\text { Provide evidence-based recommendations and measures for the appropriate PPE in urgent surgical care. } \\
\text { Recommended precautions and preventive actions in triage area, ED consultation room, induction room, } \\
\text { operating room, and recovery room are reviewed }\end{array}$ \\
\hline Coccolini et al. & $\mathrm{V}$ & $\begin{array}{l}\text { Emphasize to choose the appropriate PPEs in the whole process of surgery from transfer COVID-19 patients } \\
\text { to designated operating room to recovery room. All hospitals should organize dedicated protocols and } \\
\text { workforce training as part of the effort to face the current pandemic }\end{array}$ \\
\hline
\end{tabular}


Table 2 Levels of PPE available

\begin{tabular}{ll}
\hline Protection level & Personal protective equipment (PPE) \\
\hline Level one & Disposable surgical cap \\
& Disposable surgical mask \\
& Work uniform \\
& Disposable latex gloves or/and dispos- \\
able isolation clothing if necessary \\
Disposable surgical cap \\
Medical protective mask (N95) \\
Work uniform \\
Disposable medical protective uniform \\
Disposable latex gloves \\
Goggles \\
Disposable surgical cap \\
Work uniform \\
Disposable medical protective uniform \\
Disposable latex gloves \\
Powered air purifying respirator \\
(PAPR) or full-face respiratory pro- \\
tective devices ${ }^{\mathrm{a}}$ \\
\hline
\end{tabular}

${ }^{\text {a }}$ Due to the limited quantity of PAPR, N95/FFP2 mask and full-face respiratory protective devices are sometimes used instead

fluids of the wounded. Before arriving at the scene, all the healthcare workers and drivers involved in the pre-hospital emergency should take level-two PPE. For patients with contact with COVID-19 patients or exhibiting the symptoms of fever and/or respiratory symptoms, the pre-hospital emergency healthcare workers and drivers in the non-pandemic area should take level-two PPE in advance.

\section{Transportation of the trauma patient to hospital}

In principle, all the injured patients should be transported to the nearest hospital with proper isolation facilities, adequate levels of PPE and the ability to diagnose and treat COVID19 patients. The ambulance is exposed to high concentration of aerosol for a long time in a relatively closed environment, and must be cleaned and disinfected thoroughly [4, 17, 31-33, 45]. Negative pressure ambulances are preferred. Only patients with excluded infection of COVID-19 can be sent to the general emergency department, the rest should be sent to the COVID-19-designated hospital for treatment.

\section{Protection of healthcare workers in the emergency room (ER)}

All staff who receive patients with suspected or confirmed COVID-19 need at least level-two PPE in the emergency room (ER) [1, 11, 31, 35, 45] (Table 2). If the patient is unconscious, or his/her family members cannot describe the epidemiological history, the suspected cases shall be treated as COVID-19. During pandemic, all patients should be treated as suspected cases of COVID-19 (Table 3). Adequate
Table 3 Screening item for all patients admitted during the epidemic period of COVID-19

\begin{tabular}{ll}
\hline Number & Screening item \\
\hline 1 & The 2019-nCoV specific antibodies test \\
2 & A chest CT scan \\
3 & The 2019-nCoV nucleic acid test ${ }^{\mathrm{a}}$ \\
\hline
\end{tabular}

All patients admitted during the epidemic period of COVID-19 and caregivers should be screened by the 2019-nCoV specific antibodies test, chest CT scan, and the 2019-nCoV nucleic acid test

${ }^{a}$ The 2019-nCoV nucleic acid test can be screened twice for patients on admission if the first is negative

PPE and disinfection of medical equipment is paramount $[17,32,33,45]$.

\section{Diagnosis of COVID-19}

If possible, the hospital personnel should take sputum, nasopharynx swab or blood samples using real-time fluorescent RT-PCR to rapidly detect viral nucleic acid or gene sequencing to make the final diagnosis. According to the guidelines [33], the physicians should make a suspected or confirmed diagnosis of COVID-19. If the patients who are sent to the emergency room are preliminarily assessed as suspected COVID-19, they might be transferred immediately to complete a chest CT scan [13,31,33]. All patients admitted should be screened for 2019-nCoV (Table 3) [13, 30, 31, 39], and COVID-19 needs to be differentiated from traumatic wet lung.

In the pandemic area, the patients who do not need emergency surgery are admitted to the emergency buffer ward in single room isolation, and treated as suspected cases of COVID-19. After screening for COVID-19 (Table 3), COVID-19 negative patients can be transferred to the general ward in a single room, minimizing the number of family caregivers (at most 1 member) and forbidding other family members to visit $[30,39]$. Caregivers should be screened for COVID-19 [14, 39] (Table 3), and must be negative. Confirmed cases can be admitted in the same negative-pressure isolation ward with multiple persons. Severe or critical patients can be admitted to the intensive care unit as soon as possible [31, 46].

\section{Indications for emergency surgery}

The criteria for emergency surgery is "threat to the patient's life if surgery or procedure is not performed, threat of permanent dysfunction of an extremity or organ system, risk of metastasis or progression of staging, risk of rapidly worsening to severe symptoms" $[27,35,37,42]$. The main indications for emergency surgery at our center are: trauma seriously endangering life or limb [5, 14, 22], such 
as fracture with hemorrhagic shock, suspected large blood vessel injuries and fracture with important organ injuries; Gustilo II-III open fractures, closed fracture with compartment syndrome, fracture with severe infection; unstable pelvic fractures and failure of closed reduction in dislocation of the hip joint with/without acetabular fracture $[6,8,12,38]$; unstable spine fracture with spinal cord injury (AIS grade $\mathrm{C}$ or below), or progressive aggravation of neurological dysfunction with/without Spinal Cord Compartment Syndrome (SCCS) or Spinal Cord Intramedullary Hypertension (SCImH) [15, 23, 40, 47].

Patients with mild to moderate COVID-19 are treated as above, whereas those with severe COVID-19 are more likely to be treated non-operatively (Table 4). In other words, severe COVID-19 is a relative contraindication for emergency orthopedic surgery. Patients with critical COVID-19 or those who are intolerant to operation or anesthesia are an absolute contraindication $[33,35,37,46]$.

\section{Emergency pre-operative plan}

According to patient's condition, trauma, injury type, stability, neurological function, medical equipment and technical conditions, the purpose of operation should be completed in a single approach or minimally invasive surgery as far as possible $[2,6,7,9,10,18,22]$. The team should take measures to reduce the influence of time, trauma, hemorrhage and anesthesia on patients with COVID-19. Disposable surgical instruments should be used where possible and non-operative treatment should be strongly considered [26, 33].

\section{Patient transfer to the operating room}

The COVID-19 testing is difficult to get quickly enough in an emergency setting. All emergency patients are protected according to suspected or confirmed patients [1,31,35]. All medical personnel should take level-two protective measures, using the special transfer vehicle with disposable sheets to lead patients to transfer to the negative pressure operation room through a special channel and a special lift $[1,25,31$, $32,35,41,48]$.

\section{PPE in the operating room}

The door of the operating room should be marked with a COVID-19 sign. Staff numbers should be minimized in the operating room $[1,11,35]$. Visitors to the OR should be restricted and medical personnel should not enter or leave the operating room to avoid interrupting the negative pressure. Level-three PPE is required in the operating room for all staff $[31,48,49]$, except patrol nurses/runners who can use level-two PPE. The operating room must be in a state of negative pressure $(-5 \mathrm{~Pa})$ before the operation $[11,13,41$, $43,48]$. The buffer room should be closed, and equipment should be minimized in the operating room. Staff wearing PPE in the operating room are forbidden to leave the operating room until the PPE has been removed and the operation has finished.

Patients with non-generalized anesthesia should wear surgical masks throughout the operation [11, 34, 43, 48]. For patients under general anesthesia, a breathing filter should be installed between the anesthetic mask and the respiration loop, and a breathing filter should be installed at the inhalation and exhalation end of the anesthesia machine, respectively [41, 43, 48].

\section{Operating room management}

The high-efficiency particulate air (HEPA) filters must be in use and the room should have a negative pressure [35, $41,43,48]$. After surgery, the room should be disinfected by spraying peracetic acid or hydrogen peroxide for more than two hours, and the laminar flow should be off and air supply closed. Sampling of the surfaces and air in the operation room should be tested by the hospital infection control team after the disinfection process. The next operation can

Table 4 Clinical classifications of patients with a confirmed diagnosis of COVID-19 and indications for emergency surgery

\begin{tabular}{lll}
\hline $\begin{array}{l}\text { Clinical } \\
\text { classifica- } \\
\text { tions }\end{array}$ & Clinical symptoms & Indication for emergency surgery \\
\hline $\begin{array}{l}\text { Mild } \\
\text { Moderate }\end{array}$ & $\begin{array}{l}\text { The clinical symptoms are mild and no pneumonia manifestations can be found in imaging } \\
\text { Patients have symptoms such as fever and respiratory tract symptoms, etc. and pneumonia } \\
\text { manifestations can be seen in imaging }\end{array}$ & No contra-indication due to COVID-19 \\
Severe & $\begin{array}{c}\text { Adults who meet any of the following criteria: respiratory rate } \geq 30 \text { breaths } / \text { min; oxygen } \\
\text { saturation } \leq 93 \% \text { at a rest state; arterial partial pressure of oxygen }\left(\mathrm{PaO}_{2}\right) / \text { oxygen con- }\end{array}$ & Relative contraindication \\
& $\begin{array}{l}\text { centration }\left(\mathrm{FiO} \mathrm{O}_{2}\right) \leq 300 \text { mmHg. Patients with }>50 \% \text { lesions progression within } 24-48 \mathrm{~h} \\
\text { in lung imaging should be treated as severe cases } \\
\text { Meeting any of the following criteria: occurrence of respiratory failure requiring mechani- } \\
\text { cal ventilation; presence of shock; other organ failure that requires monitoring and } \\
\text { treatment in the ICU }\end{array}$ & Absolute contraindication \\
& &
\end{tabular}


be continued only after the monitoring results are qualified $[33,43,48]$.

\section{Prevention of surgical aerosol during surgery}

Surgery using the electrocautery, ultrasonic bone knife, drill, pulsatile lavage and other powered equipment result in aerosolization of blood, bone, and tissue fluid [20]. COVID-19 is present in all body fluids and so will be present in this aerosol. Limitation of the use of these procedures will minimize the aerosol [20, 49]. Hirschmann et al. reported that orthopedic surgery in particular to the lower limb produces vast amounts of aerosols when high-speed power tools are used, and orthopedic surgeons should use FFP2-3 or N95-99 respirator masks [20].

The ability for the aerosol to cause infection of the surgical team is unknown and dependent on the PPE worn by the surgical team. Smoke generated should be removed by an aspirator (note that suction also generates an aerosol) [49]. During the operation, normal saline for flushing should be minimized, splashing of the patient's body fluids should be avoided, and the residue of the fluid should be reduced as much as possible to prevent the pollution of the surrounding environment [20,49]. The surgical team need to cooperate closely to prevent smoke from electrocautery, splashing of the patient's body fluid, and sharp instrument injury $[1,11$, $35,48]$.

\section{Disinfection of surgical instruments}

Surgical instruments that have been directly exposed to the patient's body fluid should be immediately scrubbed with 1000-2000 mg/L chlorine-containing preparation, and then placed into double-layer yellow medical waste bags, labeled with 2019-nCoV, and immediately inform the disinfection and supply center to take them away $[32,33]$.

\section{Postoperative management}

Medical staff are advised to take appropriate protective measures according to the patient with/without COVID-19 and the environment which they are exposed in their work (Table 5). Preoperative chest CT scan $[13,31,46]$ is an important investigation for clinical diagnosis of COVID19 , as well as diagnosing lung injury caused by high-energy trauma. Nevertheless, nucleic acid testing for COVID-19 or virus sequencing should be done as soon as possible after surgery. The body temperature of patients should be monitored at least three times a day after operation. For patients with COVID-19, wound infection should not be judged only by the results of blood tests and body temperature [3]. Consider whether fever is caused by a wound infection or COVID-19 [46].

\section{Management of elective surgery}

For patients undergoing a routine operation, if COVID-19 has been excluded, the surgery should be arranged with the normal treatment procedure according to the patient's priority; healthcare workers should take level 1 protective measures at least during surgery. For patients with surgery contraindicated in the early stage or other reasons such as conservative treatment failure, fear of hospitalization during the pandemic, etc., surgery can be performed according to treatment experience for delayed union [10, 25], referring to the aforementioned protective measures. During the transition period, it is necessary to strengthen the monitoring and protection of patients and family caregivers $[13,30,39]$.

\section{Discharge and post-discharge management}

For patients without COVID-19, discharge should be scheduled time after surgery to reduce cross-infection in the hospital [31, 34]. After being discharged from the hospital, an online outpatient clinic or telemedicine can be used to guide the patient's follow-up treatment $[1,27,28$, $30,39,50]$. At the same time, it is necessary to continue to strengthen the monitoring and protection of patients and family caregivers, and pay attention to the possibility of positive viral etiology test results in patients recovered from COVID-19 [14, 26, 31, 46].

\section{Conclusion}

Strict protection at every step in the patient pathway is important to reduce the risk of cross-infection during pandemic. Lessons learnt from our experience provide some recommendations of protective measures during the entire diagnosis and treatment process of traumatic patients and help others to manage orthopedic patients with COVID19 , to reduce the risk of cross-infection between patients and to protect healthcare workers during work. 
Table 5 What PPE should be worn, and what steps done, by healthcare workers in different areas of the patient pathway (prehospital, emergency room, inpatient ward, OR, outpatients)

\begin{tabular}{|c|c|c|c|c|}
\hline \multirow[t]{2}{*}{ Sites } & \multicolumn{2}{|c|}{ Prior to COVID-19 pandemic } & \multirow{2}{*}{$\begin{array}{l}\text { During a } \\
\text { COVID-19 } \\
\text { pandemic }\end{array}$} & \multirow[t]{2}{*}{ Specific advice/important knowledge } \\
\hline & $\begin{array}{l}\text { No history } \\
\text { of epidemic } \\
\text { exposure }\end{array}$ & $\begin{array}{l}\text { Epidemiological } \\
\text { exposure history }\end{array}$ & & \\
\hline On-site first aid & Level one & Level two & Level two & $\begin{array}{l}\text { Beware: all body fluids can contain COVID-19 virus (vomit, } \\
\text { urine, blood, sputum) } \\
\text { When in a pandemic, all patients are suspected of having } \\
\text { COVID-19 }\end{array}$ \\
\hline Ambulance & Level one & Level two & Level two & $\begin{array}{l}\text { Beware: the ambulance environment receives a high level of } \\
\text { aerosol } \\
\text { Negative pressure ambulances are preferred }\end{array}$ \\
\hline Emergency room & Level one & Level two & Level two & $\begin{array}{l}\text { Test for COVID-19 ASAP } \\
\text { CT scan chest for all (appearances of COVID-19 are different } \\
\text { to traumatic wet lung) } \\
\text { Infection staff needed as part of the trauma team }\end{array}$ \\
\hline Patient transfer in hospital & Level one & Level two & Level two & Use special transfer, a special channel and a special lift \\
\hline Operating room & Level one & Level two & Level three & $\begin{array}{l}\text { Severe COVID-19 is a relative contra indication to emergency } \\
\text { orthopedic surgery and critical COVID-19 is an absolute } \\
\text { contra indication } \\
\text { Level } 3 \text { PPE for all staff except runners who are level-two } \\
\text { Label door with COVID-19 } \\
\text { Minimal staff numbers in the OR } \\
\text { Conversion of a positive pressure to a negative pressure of } \\
-5 \text { Pa should be confirmed prior to starting surgery } \\
\text { All patients should have masks if awake or exhaust filters if } \\
\text { under general anesthesia } \\
\text { Remove the smoke from electrocautery quickly. Reduce irri- } \\
\text { gation. Minimize splashing of the patient's body fluid } \\
\text { Hand disinfection is done before removing PPE }\end{array}$ \\
\hline Isolation wards & Level two & Level two & Level two & $\begin{array}{l}\text { Beware: a high level of aerosol when performing high-risk } \\
\text { procedures such as sampling from respiratory tract, intuba- } \\
\text { tion, tracheotomy, CPR, and etc., Level three PPE is required }\end{array}$ \\
\hline General wards & Level one & Level one & Level one & $\begin{array}{l}\text { Pay attention to body temperature, respiratory symptom, and } \\
\text { screening when necessary } \\
\text { Small probability that incubation period may be as long as } \\
24 \text { days }\end{array}$ \\
\hline Outpatients & Level one & Level two & Level two & $\begin{array}{l}\text { Online outpatient clinic is preferred } \\
\text { Pay attention to body temperature, respiratory symptom and } \\
\text { epidemiological exposure history } \\
\text { Pay attention to the possibility of positive viral etiology test } \\
\text { results in patients recovered from COVID-19 }\end{array}$ \\
\hline
\end{tabular}

Acknowledgements The authors wish to thank healthcare workers who are fighting in the war of prevention and control of COVID-19.

Funding This study was supported by National Natural Science Foundation of China $(81873999,81672158)$ and National Key R\&D Program of China (2016YFC1100100). These funding agencies had no role in study design, collection/analyses of data, decision to publish, or manuscript preparation.

\section{Compliance with ethical standards}

Conflict of interest The authors declare that they have no conflict of interest.
Ethical approval Ethical approval was not required, as this was a pure review of the literature that did not involve humans or animals.

\section{References}

1. Awad ME, Rumley JCL, Vazquez JA, Devine JG (2020) Peri-operative considerations in urgent surgical care of suspected and confirmed COVID-19 orthopedic patients: operating rooms protocols and recommendations in the current COVID-19 pandemic. J Am Acad Orthop Surg. https://doi.org/10.5435/JAAOS-D-20-00227

2. Ayoub M (2010) Is it possible that most of the displaced acetabular fractures can be managed through a single ilioinguinal 
approach? 2-7 years experience results. Eur J Orthop Surg Traumatol 21(4):259-267. https://doi.org/10.1007/s00590-010-0704-7

3. Ban KA, Minei JP, Laronga C et al (2017) American College of Surgeons and Surgical Infection Society: surgical site infection guidelines, 2016 update. J Am Coll Surg 224(1):59-74. https:// doi.org/10.1016/j.jamcollsurg.2016.10.029

4. Cai J, Sun W, Huang J, Gamber M, Wu J, He G (2020) Indirect virus transmission in cluster of COVID-19 cases, Wenzhou, China, 2020. Emerg Infect Dis. https://doi.org/10.3201/eid26 06.200412

5. Chen HW, Liu GD, Wu LJ (2015) Clinical and radiological outcomes following arthroscopic-assisted management of tibial plateau fractures: a systematic review. Knee Surg Sports Traumatol Arthrosc 23(12):3464-3472. https://doi.org/10.1007/s0016 7-014-3256-2

6. Chen K, Yao S, Yang F et al (2019) Minimally invasive screw fixation of unstable pelvic fractures using the "blunt end" Kirschner wire technique assisted by 3D printed external template. Biomed Res Int 2019:1524908. https://doi.org/10.1155/2019/1524908

7. Chen K, Yang F, Yao S et al (2019) Application of computerassisted virtual surgical procedures and three-dimensional printing of patient-specific pre-contoured plates in bicolumnar acetabular fracture fixation. Orthop Traumatol Surg Res 105:877-884. https ://doi.org/10.1016/j.otsr.2019.05.011

8. Chen K, Yang F, Yao S et al (2020) Biomechanical comparison of different fixation techniques for typical acetabular fractures in the elderly. J Bone Jt Surg Am. https://doi.org/10.2106/JBJS.19.01027

9. Chen K, Ji Y, Huang Z et al (2018) Single modified ilioinguinal approach for the treatment of acetabular fractures involving both columns. J Orthop Trauma 32:e428-e434. https://doi.org/10.1097/ BOT.0000000000001303

10. Schlundt C, Bucher CH, Tsitsilonis S et al (2018) Clinical and research approaches to treat non-union fracture. Curr Osteoporos Rep 16(2):155-168. https://doi.org/10.1007/s11914-018-0432-1

11. Coccolini F, Perrone G, Chiarugi M et al (2020) Surgery in COVID-19 patients: operational directives. World J Emerg Surg 15(1):25. https://doi.org/10.1186/s13017-020-00307-2

12. Cothren CC, Osborn PM, Moore EE (2007) Preperitonal pelvic packing for hemodynamically unstable pelvic fractures: a paradigm shift. J Trauma 62(4):834-839. https://doi.org/10.1097/ TA.0b013e31803c7632 (discussion 839-842)

13. De Caro F, Hirschmann TM, Verdonk P (2020) Returning to orthopaedic business as usual after COVID-19: strategies and options. Knee Surg Sports Traumatol Arthrosc. https://doi. org/10.1007/s00167-020-06031-3

14. DePhillipo NN, Larson CM, O'Neill OR et al (2020) Guidelines for ambulatory surgery centers for surgically necessary/time-sensitive the care of orthopaedic cases during the COVID-19 Pandemic. J Bone Jt Surg Am. https://doi.org/10.2106/JBJS.20.00489

15. Donnally CJ 3rd, Shenoy K, Vaccaro AR et al (2020) Triaging spine surgery in the COVID-19 era. Clin Spine Surg. https://doi. org/10.1097/BSD.0000000000000988

16. Ducournau F, Arianni M, Awwad S et al (2020) COVID-19: initial experience of an international group of hand surgeons. Hand Surg Rehab. https://doi.org/10.1016/j.hansur.2020.04.001

17. General Office of the national health and Health Commission. Notice of novel coronavirus infection office in the office of the national health and Health Commission for medical waste management. https://www.gov.cn/zhengce/zhengceku/2020-01/28/ content 5472796.htm.

18. Gereli A, Kocaoglu B, Ulku KT et al (2015) Are pelvic anatomical structures in danger during arthroscopic acetabular labral repair? Definition of safe bone depth. Knee Surg Sports Traumatol Arthrosc 25(1):45-49. https://doi.org/10.1007/s00167-015-3797-z
19. Guo X, Wang J, Hu D et al (2020) Survey of COVID-19 disease among orthopaedic surgeons in Wuhan, People's Republic of China. J Bone Jt Surg Am. https://doi.org/10.2106/JBJS.20.00417

20. Hirschmann MT, Hart A, Henckel J, Sadoghi P, Seil R, Mouton C (2020) COVID-19 coronavirus: recommended personal protective equipment for the orthopaedic and trauma surgeon. Knee Surg Sports Traumatol Arthrosc. https://doi.org/10.1007/s00167-02006022-4

21. Huang H, Sharma H, Chen L, Saberi H, Mao G (2019) 2018 yearbook of neurorestoratology. J Neurorestoratol 7:8-17. https://doi. org/10.26599/JNR.2019.9040003

22. Isaacs-Itua A, Sedki I (2018) Management of lower limb amputations. Br J Hosp Med (Lond) 79(4):205-210. https://doi. org/10.12968/hmed.2018.79.4.205

23. Badhiwala JH, Ahuja CS, Fehlings MG (2018) Time is spine: a review of translational advances in spinal cord injury. J Neurosurg Spine 30(1):1-18. https://doi.org/10.3171/2018.9.SPINE18682

24. Johns Hopkins University. Coronavirus COVID-19 Global Cases by the Center for Systems Science and Engineering (CSSE) at Johns Hopkins University. https://www.arcgis.com/apps/opsda shboard/index.html\#/bda7594740fd40299423467b48e9ecf6.

25. Kim H, Baek JH, Park SM, Ha YC (2014) Arthroscopic reduction and internal fixation of acetabular fractures. Knee Surg Sports Traumatol Arthrosc 22(4):867-870. https://doi.org/10.1007/s0016 7-013-2799-y

26. Li Y, Li ZF, Mao QX et al (2020) Consensus on emergency surgery and infection prevention and control for severe trauma patients with 2019 novel coronavirus pneumonia. Chin J Trauma 36(2):97-103. https://doi.org/10.3760/cma.j.i ssn.0253-2352.2020.05.003

27. Massey PA, McClary K, Zhang AS, Savoie FH, Orthopaedic BRS (2020) Surgical selection and inpatient paradigms during the coronavirus COVID-19 pandemic. J Am Acad Orthop Surg. https:// doi.org/10.5435/JAAOS-D-20-00360

28. Mauffrey C, Trompeter A (2020) Lead the way or leave the way: leading a Department of Orthopedics through the COVID-19 pandemic. Eur J Orthop Surg Traumatol 30(4):555-557. https://doi. org/10.1007/s00590-020-02670-x

29. Mi B, Chen L, Xiong Y, Xue H, Zhou W, Liu G (2020) Characteristics and early prognosis of COVID-19 infection in fracture patients. J Bone Jt Surg Am. https://doi.org/10.2106/ JBJS.20.00390

30. Stillman MD, Capron M, Alexander M et al (2020) COVID-19 and spinal cord injury and disease: results of an international survey. Spinal Cord Ser Cases 6(1):21. https://doi.org/10.1038/s4139 4-020-0275-8

31. National Health Commission of the People's Republic of China, State Administration of Traditional Chinese Medicine. Prevention and Control Protocols of Novel Coronavirus Pneumonia (Pilot version 7 modified). https://www.nhc.gov.cn/yzygj/s7653p/20200 3/46c9294a7dfe4cef80dc7f5912eb1989/files/ce3e6945832a438 eaae415350a8ce964.pdf.

32. National Health Commission of the People's Republic of China. Transport plan for novel coronavirus infection cases (Trial). https ://www.gov.cn/zhengce/zhengceku/2020-01/29/content_54728 94.htm.

33. National Health Commission of the People's Republic of China. Notice on Printing novel coronavirus infection prevention and control technical guidelines (First Edition) in medical institutions. https://www.nhc.gov.cn/xcs/yqfkdt/202001/b91fdab7c3 04431eb082d67847d27e14.shtml.

34. Randell PS, Compagnoni R (2020) Management of orthopaedic and traumatology patients during the Coronavirus disease (COVID-19) pandemic in northern Italy. Knee Surg Sports Traumatol Arthrosc. https://doi.org/10.1007/s00167-020-06023-3 
35. Rodrigues-Pinto R, Sousa R, Oliveira A et al (2020) Preparing to perform trauma and orthopaedic surgery on patients with COVID19. J Bone Jt Surg Am. https://doi.org/10.2106/JBJS.20.00454

36. Rothe C, Schunk M, Sothmann P, Bretzel G, Froeschl G, Wallrauch $\mathrm{C}$ et al (2020) Transmission of 2019-nCoV infection from an asymptomatic contact in Germany. N Engl J Med 382(10):970 971. https://doi.org/10.1056/NEJMc2001468

37. Sarac NJ, Sarac BA, Schoenbrunner AR et al (2020) A review of state guidelines for elective orthopaedic procedures during the COVID-19 outbreak. J Bone Jt Surg Am. https://doi.org/10.2106/ JBJS.20.00510

38. Schmal H, Froberg L, Larsen MS et al (2018) Evaluation of strategies for the treatment of type $\mathrm{B}$ and $\mathrm{C}$ pelvic fractures. Bone Joint J 100-B(7):973-983. https://doi.org/10.1302/0301-620X.100B7 .BJJ-2017-1377.R1

39. Stinner DJ, Lebrun C, Hsu JR, Jahangir AA, Mir HR (2020) The orthopaedic trauma service and COVID-19-practice considerations to optimize outcomes and limit exposure. J Orthop Trauma. https://doi.org/10.1097/BOT.0000000000001782

40. Telemacque D, Zhu F, Chen K et al (2018) Method of decompression by durotomy and duroplasty for cervical spinal cord injury in patients without fracture or dislocation. J Neurorestoratol 6(1):158-164. https://doi.org/10.26599/jnr.2018.9040017

41. Ti LK, Ang LS, Foong TW, Ng BSW (2020) What we do when a COVID-19 patient needs an operation: operating room preparation and guidance. Can J Anaesth. https://doi.org/10.1007/s1263 0-020-01617-4

42. Vannabouathong C, Devji T, Ekhtiari S et al (2020) Novel coronavirus COVID-19 current evidence and evolving strategies. J Bone Jt Surg Am. https://doi.org/10.2106/JBJS.20.00396

43. Wax RS, Christian MD (2020) Practical recommendations for critical care and anesthesiology teams caring for novel coronavirus (2019-nCoV) patients. Can J Anaesth 67(5):568-576. https:// doi.org/10.1007/s12630-020-01591-x

44. World Health Organization (WHO). Novel coronavirus (2019$\mathrm{nCoV}$ ) situation report. 2020. https://www.who.int/docs/defau 1tsource/coronaviruse/situation-reports/20200121-sitrep-1-2019ncov.pdf?sfvrsn=20a99c10_4

45. World Health Organization. Infection prevention and control during health care when COVID-19 is suspected. Interim Guidance. 2020. https://www.who.int/publications-detail/infection-prevention-and-control-during-health-care-when-novel-coronavirus(ncov)-infection-is-suspected-20200125.

46. Wu Z, McGoogan JM (2020) Characteristics of and important lessons from the coronavirus disease 2019 (COVID-19) outbreak in China: summary of a report of 72314 cases from the Chinese Center for Disease Control and Prevention. JAMA. https://doi. org/10.1001/jama.2020.2648

47. Kang Yi, Ding H, Zhou H et al (2018) Epidemiology of worldwide spinal cord injury: a 307 literature review. J Neurorestoratol 6:1-9. https://doi.org/10.2147/jn.s143236

48. Zhao S, Ling K, Yan H et al (2020) Anesthetic management of patients with suspected or confirmed 2019 novel coronavirus infection during emergency procedures. J Cardiothorac Vasc Anesth 34(5):1125-1131. https://doi.org/10.1053/j. jvca.2020.02.039

49. Zheng MH, Boni L, Fingerhut A (2020) Minimally invasive surgery and the novel coronavirus outbreak: lessons learned in China and Italy. Ann Surg. https://doi.org/10.1097/SLA.0000000000 003924

50. Zou J, Yu H, Song D, Niu J, Yang H (2020) Advice on standardized diagnosis and treatment for spinal diseases during the coronavirus disease 2019 pandemic. Asian Spine J 14(2):258-263. https ://doi.org/10.31616/asj.2020.0122

Publisher's Note Springer Nature remains neutral with regard to jurisdictional claims in published maps and institutional affiliations. 